\title{
The clinical evaluation of novel polymethyl methacrylate membrane with a modified membrane surface: a multicenter pilot study
}

Nobuko Uchiumi ${ }^{1 *}$, Koji Sakuma ${ }^{1}$, Sumihiko Sato ${ }^{1}$, Yoshinaga Matsumoto ${ }^{2}$, Hirotada Kobayashi ${ }^{2}$, Koki Toriyabe ${ }^{3}$, Katsumi Hayashi ${ }^{3}$, Tadayuki Kawasaki ${ }^{3}$, Takashi Watanabe ${ }^{3}$, Ayumi Itohisa ${ }^{4}$, Masanori Yokota ${ }^{4}$, Katsumi Okazawa ${ }^{5}$ and Noriyoshi Murotani ${ }^{5}$

\begin{abstract}
Background: Polymethyl methacrylate (PMMA) membranes have the unique property of adsorption, which can remove medium- and large-weight molecular substances that cannot be removed by normal hemodialysis and hemodiafiltration. Filtryzer ${ }^{\circledast}$ NF (NF) is a newly developed PMMA membrane that suppresses platelet adhesion on the membrane surface and retains an adsorption property. NF is expected to improve inflammatory conditions and clinical symptoms in hemodialysis patients compared with conventional PMMA membranes.

Methods: Thirty-seven maintenance hemodialysis patients treated with polysulfone (PS) membranes and who had detectable chronic inflammation were enrolled into the study. The patients were randomly allocated into the NF and PS groups and observed for 1 year. C-reactive protein (CRP) values were measured as the primary endpoint. Nutrition, blood cell count, and dialysis itchiness were evaluated as secondary endpoints.

Results: Significant differences in CRP values were not found between the NF and PS groups. In the PS group, the creatinine generation rate (\%CGR) and platelet count, which were included in nutrition and blood cell count, respectively, significantly decreased after 6 and 9 months compared with the start of study, but these parameters did not significantly change in the NF group within 1 year. Dialysis itchiness in the NF group was significantly improved compared with the PS group after 9 months.
\end{abstract}

Conclusions: Our results showed that a new PMMA membrane, NF, has a potential to maintain nutritional conditions and the platelet counts and improve dialysis itchiness.

Trial registration: This study is retrospectively registered with the Clinical Trials Registry of the University Hospital Medical Information Network on February 17, 2015 (registration ID, UMIN000016567).

Keywords: Hemodialysis, Polymethyl methacrylate, PMMA membranes, Platelet count, Dialysis itchiness, Creatinine generation rate, Filtryzer ${ }^{\circledast \mathrm{NF}}$

\footnotetext{
* Correspondence: uchiumi@3109jp.com

${ }^{1}$ Credo Sato Clinic, 2138-1, Wakamatsu-cho, Wakaba-ku, Chiba City, Chiba

264-0021, Japan

Full list of author information is available at the end of the article
}

(c) The Author(s). 2018 Open Access This article is distributed under the terms of the Creative Commons Attribution 4.0 International License (http://creativecommons.org/licenses/by/4.0/), which permits unrestricted use, distribution, and 


\section{Background}

Polymethyl methacrylate (PMMA) hollow fiber membranes have an adsorption property for proteins including $\beta 2$-microglobulin, interleukin-6, and albumin, and it can remove high molecular weight proteins that are not removed efficiently by hemodialysis or hemodiafiltration $[1,2]$. Hemodialysis therapy using a PMMA dialyzer shows antiinflammatory effects $[3,4]$ and improves anemia $[5,6]$, itchiness $[7,8]$, nutritional status [9], and immune responses [10, 11]. These clinical findings are thought to be caused by removal of high molecular weight proteins by adsorption.

Filtryzer $^{\bullet} \mathrm{NF}$ (NF) is the new PMMA dialyzer with an improved hemocompatibility that results from reforming its surface and it also has a protein adsorption property, which is similar to previous PMMA dialyzers [12, 13]. Oshihara et al. reported that for NF, fibrinogen adsorption and platelet adhesion on the membrane were less than that of the conventional PMMA membrane, Filtryzer $^{\oplus}$ BG (BG) [12]. Additionally, Masakane et al. reported that changes in the platelet count and peripheral circulation blood pressure during dialysis were less than that observed with the BG membrane [13].

To investigate the usefulness of NF, we conducted a 1-year observational study comparing the NF and polysulfone (PS) membranes used for hemodialysis patients with chronic inflammation.

\section{Methods}

\section{Subjects}

Maintenance hemodialysis patients who were treated at seven participating dialysis centers were enrolled. Inclusion criteria were as follows: received hemodialysis three times a week using a PS dialyzer and chronic inflammation $(0.2 \mathrm{mg} / \mathrm{dL} \leq$ serum $\mathrm{C}$-reactive protein (CRP) levels $<2.0 \mathrm{mg} / \mathrm{dL}$, based on Ridker [14]). Exclusion criteria were as follows: dialysis duration $\leq 1$ year; elderly patients over the age of 80 years; serum albumin level less than $3.0 \mathrm{~g} / \mathrm{dL}$; occurrence of events involving the brain or heart within 3 months before the study; or having an inflammatory disease or active infection.

\section{Study design}

A flow diagram of this study is presented in Fig. 1. The enrolled patients were randomly allocated to dialysis using NF (NF group) or PS (PS group). After allocation, patients in the NF group were switched from the PS membrane to the NF membrane. The following evaluation items were collected every 3 months: CRP; normalized protein catabolic rate (nPCR); \% creatinine generation rate (\%CGR); serum albumin; Mini Nutrition Assessment ${ }^{\oplus}$-short form (MNA-SF); body weight; blood cell counts including white blood cells (WBCs), red blood cells (RBCs), and platelets; and dialysis itchiness.

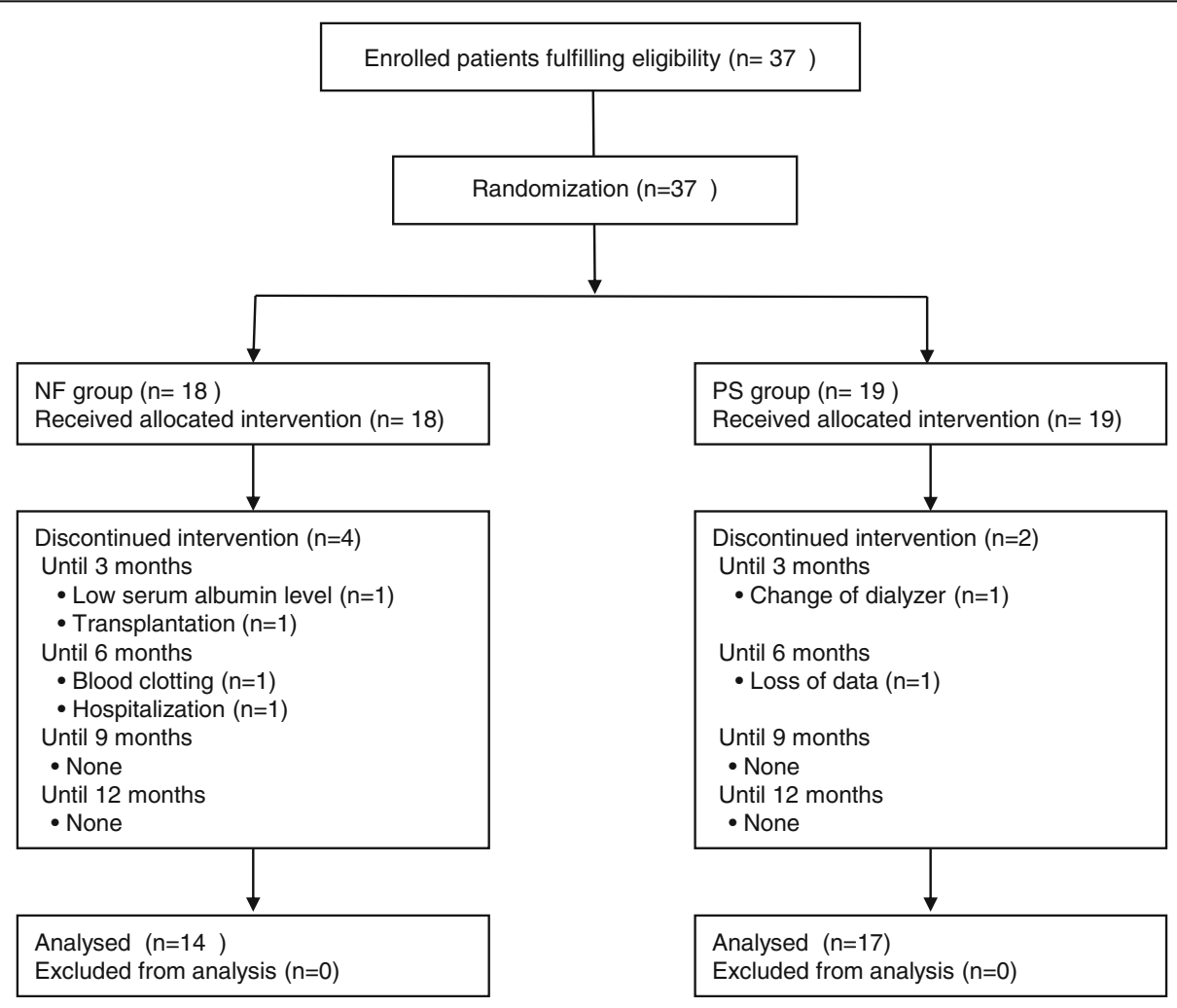

Fig. 1 Flow diagram of this study 
\%CGR was calculated in accordance with previous report [15]. MNA-SF was conducted in accordance with a previous report [16]. Dialysis itchiness was evaluated using a visual analog scale (VAS) inspection, as described in previous reports $[17,18]$.

Patients were withdrawn from this study if the following incidents occurred: allergic reaction; blood pressure drop immediately after the start of the dialysis session; abnormal clinical finding; adverse events that were causality to suspected to be caused by hemodialyzers; serum albumin level that fell below $3.0 \mathrm{~g} / \mathrm{dL}$; the patient chose to withdraw; or if the doctor judged that patients should withdraw from this study.

\section{Randomization}

The enrolled patients were listed by Japanese alphabetical order in each dialysis center, and then randomly allocated to NF and PS groups.

\section{Ethical considerations}

This study conforms to the terms set forth in the Declaration of Helsinki and was approved by the Institutional Review Board of JCHO Chiba Hospital. Informed consent was obtained from all participating patients before the eligibility determination and the study entry.

\section{Clinical trials registry}

This study is registered with the Clinical Trials Registry of the University Hospital Medical Information Network (UMIN-CTR) on February 17, 2015 (registration ID, UMIN000016567) https://upload.umin.ac.jp/cgi-open-bin/ ctr/ctr_view.cgi? recptno=R000019222.

This study was retrospectively registered with UMINCTR because a first patient had been participated on June 10th, 2014. The reason why this study was retrospectively registered was lack of awareness of the prospective registration requirement.

\section{Data and statistical analysis}

Data analysis was conducted after excluding data of patients who were withdrawn. Results are presented as the mean \pm standard deviation. Statistical analysis was performed using StatFlex (Artech Co., Ltd., Osaka, Japan). MNA-SF results between the NF and PS groups were compared using the Mann-Whitney $U$ test. For comparison items, except for MNA-SF, between two groups, an unpaired Student's $t$ test or Welch's $t$ test was used as appropriate. Comparison of MNA-SF results within each group was performed using the Friedman test. For comparison of evaluation items, except for MNA-SF, within each group, Dunnett's test was used after a repeated

Table 1 Characteristics of enrolled patients

\begin{tabular}{|c|c|c|c|}
\hline Items & NF group & PS group & \\
\hline Number of patient & 18 & 19 & \\
\hline Sex (male/female) & $15 / 3$ & $12 / 7$ & n.s. \\
\hline Age (years) & $60.3 \pm 10.1$ & $58.2 \pm 8.3$ & n.s. \\
\hline Dialysis duration (years) & $8.7 \pm 7.1$ & $10.5 \pm 5.9$ & n.s. \\
\hline Medical history for diabetes $(\mathrm{Y} / \mathrm{N})^{\#}$ & $6 / 12$ & $8 / 11$ & n.s. \\
\hline \multicolumn{4}{|l|}{ Original disease } \\
\hline Chronic glomerulonephritis & 7 & 6 & n.s. \\
\hline Diabetic nephropathy & 5 & 7 & \\
\hline IgA nephropathy & 1 & 1 & \\
\hline Nephrosclerosis & 2 & 1 & \\
\hline Polycystic kidney & 1 & 1 & \\
\hline A drop in renal function by chronic rejection after renal transplant & 1 & 0 & \\
\hline Unknown & 1 & 3 & \\
\hline Dialysis time (hours) & $4.1 \pm 0.3$ & $4.3 \pm 0.5$ & n.s. \\
\hline Blood flow rate (mL/min) & $226 \pm 23$ & $234 \pm 34$ & n.s. \\
\hline Surface area $\left(m^{2}\right)$ & $2.0 \pm 0.3$ & $2.0 \pm 0.3$ & n.s. \\
\hline \multicolumn{4}{|l|}{ KoA } \\
\hline Polysulfone/polyether sulfone & $1336 \pm 296$ & $1380 \pm 285$ & n.s. \\
\hline NF & $1202 \pm 90$ & - & \\
\hline Membrane material (polysulfone/polyether sulfone) & $11 / 7$ & $10 / 9$ & n.s. \\
\hline Dialysate (without acetate/ with acetate) & $5 / 13$ & $6 / 13$ & n.s. \\
\hline
\end{tabular}

n.s. not significant, NF Filtryzer ${ }^{\circledR} \mathrm{NF}, P S$ polysulfone

\#Patients who had developed diabetes after the initiation of dialysis were included 
measures one-way ANOVA. Categorical variables were tested using the chi-square test. $P<0.05$ was considered to be significant.

\section{Results}

\section{Overview of this study}

In this study, 37 patients who met the eligibility criteria were enrolled and randomly allocated to the NF or PS group. There were 18 and 19 patients in the NF and PS group, respectively. No significant difference was detected in any of the subject characteristics and evaluation items between the two groups (Tables 1 and 2).

During the 12-month observation period, four patients in the NF group and two patients in the PS group were withdrawn (Fig. 1). The reasons for withdrawal in the NF group were blood clotting, decrease in serum albumin level, transplantation, and hospitalization. The reasons for withdrawal in the PS group were change of dialyzer and loss of data. The number of patients remaining in the NF and PS groups was 14 and 17, respectively. After excluding data from the withdrawn patients, subject characteristics and evaluation items at the start of this study (baseline) were not significantly different between the two groups (Tables 3 and 4).

All of participating dialysis center maintained dialysate quality according to "Standard on Microbiological

Table 2 Results of items that were evaluated in enrolled patients

\begin{tabular}{|c|c|c|c|}
\hline \multirow[t]{2}{*}{ Items } & \multicolumn{3}{|l|}{ Baseline } \\
\hline & NF group & PS group & \\
\hline Number of patients & 18 & 19 & \\
\hline CRP $(\mathrm{mg} / \mathrm{dL})$ & $0.51 \pm 0.48$ & $0.74 \pm 0.65$ & n.s. \\
\hline nPCR (g/kg/day) & $0.89 \pm 0.16$ & $0.89 \pm 0.15$ & n.s. \\
\hline \%CGR (\%) & $114 \pm 25$ & $115 \pm 21$ & n.s. \\
\hline Albumin (g/dL) & $3.6 \pm 0.3$ & $3.5 \pm 0.3$ & n.s. \\
\hline MNA-SF & $13 \pm 1$ & $13 \pm 1$ & n.s. \\
\hline \multicolumn{4}{|l|}{ MNA screening score $(n)$} \\
\hline Normal nutritional status & 17 & 18 & n.s. \\
\hline At risk of malnutrition & 1 & 1 & \\
\hline Malnourished & 0 & 0 & \\
\hline Itchiness (VAS values) & $21.6 \pm 18.3$ & $14.2 \pm 16.4$ & n.s. \\
\hline Body weight (kg) & $61.0 \pm 11.7$ & $66.1 \pm 12.7$ & n.s. \\
\hline \multicolumn{4}{|l|}{ Blood cell counts } \\
\hline White blood cell $(/ \mu \mathrm{L})$ & $6448 \pm 1925$ & $7396 \pm 2395$ & n.s. \\
\hline Red blood cell $\left(\times 10^{4} / \mu \mathrm{L}\right)$ & $356 \pm 28$ & $362 \pm 48$ & n.s. \\
\hline Platelet $\left(\times 10^{4} / \mu \mathrm{L}\right)$ & $21.9 \pm 6.3$ & $21.8 \pm 6.7$ & n.s. \\
\hline
\end{tabular}

MNA screening score: normal nutritional status, 12-14 points; at risk of malnutrition, 8-11 points; malnourished, 0-7 points

n.s. not significant, CRP C-reactive protein, \%CGR \% creatinine generation rate, nPCR normalized protein catabolic rate, MNA-SF Mini nutrition Assessmentshort form, VAS visual analog scale, NF Filtryzer ${ }^{\oplus} \mathrm{NF}$, $P S$ polysulfone
Management of Fluids for Hemodialysis and Related Therapies by the Japanese Society for Dialysis Therapy 2008" [19]. Endotoxin or microorganisms were not detected in the dialysates at any time point during the study period.

\section{CRP values}

There was no statistically significant difference in CRP values over 12 months between the NF and PS groups and within each group (Table 4).

\section{Nutrition items}

Body weight tended to decrease in both groups, and the amount of the decrease was larger in the PS group (Table 4). The rate of weight reduction from baseline to 12 months tended to be greater in the PS group compared with the NF group (not significant). In the PS group, four of 17 patients had a rate of weight reduction that was more than $5 \%$ and in the NF group, this rate of weight reduction was seen in 0 of 14 patients (Table 4, Fig. 2). In the NF group, the serum albumin level significantly decreased from baseline after 3 and 6 months, but it recovered after 9 months (Table 4). In the NF group, $\mathrm{nPCR}$, which reflected protein intake, tended to increase over 9 months. The MNA-SF scores showed that after 12 months, the number of patients who were "at risk of malnutrition" had increased from 0 to 2 in the NF group and from 1 to 4 in the PS group (Table 4). \%CGR in the NF group did not change during this study (Fig. 3a). In the PS group, \%CGR was maintained lower than baseline during this study, and especially, at 6 and 9 months was significantly lower compared with that at baseline (Fig. 3a).

\section{Blood cell counts before dialysis treatment}

Platelet counts in the PS group were significantly lower at 6 and 9 months compared with baseline, but in the NF group, the platelet count did not significantly change during the study (Fig. 3b). There was no significant difference in RBC counts and WBC counts (Table 4).

\section{Dialysis itchiness}

VAS values for dialysis itchiness in the NF group were significantly lower at 9 months compared with those of the PS group (Fig. 3c, Table 4). VAS values in the NF group at 9 months were maintained until 12 months.

\section{Discussion}

Protein energy wasting (PEW) is frequently observed in chronic kidney disease patients, especially in hemodialysis patients, and PEW substantially influences the prognosis of hemodialysis patients $[20,21]$. Because PEW has a strong relationship with inflammation and because inflammation is associated with the progress of atherosclerosis, it was 
Table 3 Characteristics of patients who completed the study and were not withdrawn

\begin{tabular}{|c|c|c|c|}
\hline Items & NF group & PS group & \\
\hline Number of patient & 14 & 17 & \\
\hline Sex (male/female) & $12 / 2$ & $11 / 6$ & n.s. \\
\hline Age (years) & $59.6 \pm 11.1$ & $57.8 \pm 7.2$ & n.s. \\
\hline Dialysis duration (years) & $7.7 \pm 6.8$ & $10.7 \pm 6.2$ & n.s. \\
\hline Medical history for diabetes $(\mathrm{Y} / \mathrm{N})^{\#}$ & $6 / 8$ & $7 / 10$ & n.s. \\
\hline \multicolumn{4}{|l|}{ Original disease $(n)$} \\
\hline Chronic glomerulonephritis & 3 & 6 & n.s. \\
\hline Diabetic nephropathy & 5 & 6 & \\
\hline IgA nephropathy & 1 & 1 & \\
\hline Nephrosclerosis & 2 & 1 & \\
\hline Polycystic kidney & 1 & 1 & \\
\hline A drop in renal function by chronic rejection after renal transplant & 1 & 0 & \\
\hline Unknown & 1 & 2 & \\
\hline Dialysis time (hours) & $4.1 \pm 0.3$ & $4.2 \pm 0.3$ & n.s. \\
\hline Blood flow rate (mL/min) & $227 \pm 23$ & $238 \pm 33$ & n.s. \\
\hline Surface area $\left(m^{2}\right)$ & $2.0 \pm 0.2$ & $2.1 \pm 0.2$ & n.s. \\
\hline \multicolumn{4}{|l|}{ KoA } \\
\hline Polysulfone/polyether sulfone & $1324 \pm 302$ & $1355 \pm 291$ & n.s. \\
\hline NF & $1193 \pm 101$ & - & \\
\hline Membrane material (polysulfone/polyether sulfone) & $9 / 5$ & $10 / 7$ & n.s. \\
\hline Dialysate (without acetate/ with acetate) & $4 / 10$ & $4 / 13$ & n.s. \\
\hline
\end{tabular}

n.s. not significant, NF Filtryzer ${ }^{\circledR}$ NF, PS polysulfone

\#Patients who had developed diabetes after the initiation of dialysis were included

recently reported that PEW and inflammation comprises malnutrition, inflammation, and atherosclerosis (MIA) syndrome [21].

Inflammatory substances such as cytokines related to the development and progress of inflammation are not efficiently removed by normal hemodialysis and hemodiafiltration because of their middle and high molecular weights. It has been reported that the PMMA membrane potentially removes these inflammatory substances via its adsorption property and improves inflammatory [22] and nutritional conditions [2, 9].

The newly developed PMMA membrane, NF, was reported to suppress platelet activation during dialysis by reforming the membrane surface and have the same adsorption property as the conventional PMMA membrane, BG $[12,13]$. Activated platelets are related directly or indirectly to the development of the inflammatory response: activated platelets release pro-inflammatory substances [23] and induce the production of pro-inflammatory substances from white blood cells by activation that is induced by forming a complex [24]. We suggest that NF probably improves inflammatory conditions by reducing pro-inflammatory cytokine production from activated platelets and WBCs and by removing serum cytokines via adsorption.
CRP is an acute-phase protein that is primarily synthesized in hepatocytes in response to proinflammatory cytokines and then it is released. CRP is a highly sensitive marker of inflammation, and it is reported to be an independent predictor of the occurrence of cardiovascular diseases $[25,26]$. In this study, we evaluated NF using CRP as an inflammation marker because we expected that NF could improve inflammatory conditions, but there was no significant difference in CRP values between the NF and PS groups. Additionally, we did not observe significant differences in CRP values when they were compared before and after the change to the NF membrane. CRP values were measured at the first session each week when the dialysis interval was the longest from the previous session. Additionally, CRP might be produced by inflammatory cytokines induced by uremic toxins that accumulate during a dialysis session, which may explain why we did not detect a reduction in CRP levels using the NF membrane. If the CRP concentrations were measured at the last dialysis session of the week, a reduction in the CRP concentration may be found.

Compared with baseline, serum albumin level in NF group significantly decreased at 3 and 6 months. We presume that this clinical finding occurred by increase of albumin loss after change of dialyzer because NF can 
Table 4 Result items that were evaluated for 12 months in patients who completed the study and were not withdrawn

\begin{tabular}{|c|c|c|c|c|c|c|c|c|c|c|}
\hline \multirow[t]{2}{*}{ Items } & \multicolumn{2}{|l|}{ Baseline } & \multicolumn{2}{|l|}{3 months } & \multicolumn{2}{|l|}{6 months } & \multicolumn{2}{|l|}{9 months } & \multicolumn{2}{|l|}{12 months } \\
\hline & NF group & PS group & NF group & PS group & NF group & PS group & NF group & PS group & NF group & PS group \\
\hline Number of patients & 14 & 17 & 14 & 17 & 14 & 17 & 14 & 17 & 14 & 17 \\
\hline CRP $(\mathrm{mg} / \mathrm{dL})$ & $0.55 \pm 0.52$ & $0.75 \pm 0.66$ & $0.53 \pm 0.60$ & $0.99 \pm 2.03$ & $0.61 \pm 0.65$ & $0.71 \pm 0.83$ & $0.68 \pm 0.88$ & $0.62 \pm 0.46$ & $0.64 \pm 0.94$ & $0.49 \pm 0.42$ \\
\hline nPCR (g/kg/day) & $0.88 \pm 0.17$ & $0.90 \pm 0.15$ & $0.89 \pm 0.16$ & $0.85 \pm 0.134$ & $0.89 \pm 0.14$ & $0.89 \pm 0.16$ & $0.91 \pm 0.16$ & $0.91 \pm 0.16$ & $0.86 \pm 0.12$ & $0.86 \pm 0.17$ \\
\hline \%CGR (\%) & $114 \pm 25$ & $115 \pm 18$ & $117 \pm 23$ & $109 \pm 21$ & $112 \pm 21$ & $107 \pm 21^{\#}$ & $117 \pm 18$ & $108 \pm 18^{\#}$ & $119 \pm 20$ & $109 \pm 24$ \\
\hline Albumin (g/dL) & $3.6 \pm 0.3$ & $3.5 \pm 0.3$ & $3.4 \pm 0.4^{\#}$ & $3.5 \pm 0.3$ & $3.4 \pm 0.3^{\#}$ & $3.6 \pm 0.3$ & $3.5 \pm 0.3$ & $3.5 \pm 0.3$ & $3.5 \pm 0.3$ & $3.5 \pm 0.3$ \\
\hline MNA-SF & $13 \pm 1$ & $13 \pm 1$ & $12 \pm 2$ & $13 \pm 1$ & $13 \pm 1$ & $13 \pm 2$ & $13 \pm 1$ & $13 \pm 1$ & $12 \pm 2$ & $13 \pm 1$ \\
\hline \multicolumn{11}{|c|}{ MNA screening score $(n)$} \\
\hline $\begin{array}{l}\text { Normal } \\
\text { nutritional status }\end{array}$ & 14 & 16 & 11 & 16 & 13 & 15 & 13 & 14 & 12 & 13 \\
\hline $\begin{array}{l}\text { At risk of } \\
\text { malnutrition }\end{array}$ & 0 & 1 & 3 & 1 & 1 & 2 & 1 & 3 & 2 & 4 \\
\hline Malnourished & 0 & 0 & 0 & 0 & 0 & 0 & 0 & 0 & 0 & 0 \\
\hline $\begin{array}{l}\text { Itchiness } \\
\text { (VAS values) }\end{array}$ & $22.1 \pm 19.8$ & $14.1 \pm 16.6$ & $21.6 \pm 17.4$ & $20.6 \pm 19.5$ & $27.9 \pm 28.9$ & $30.5 \pm 25.6$ & $12.1 \pm 20.4 \$$ & $24.7 \pm 21.0$ & $14.1 \pm 23.8$ & $19.1 \pm 19.0$ \\
\hline Body weight (kg) & $61.4 \pm 12.0$ & $66.3 \pm 13.4$ & $61.5 \pm 11.8$ & $66.0 \pm 12.7$ & $61.2 \pm 11.5$ & $65.7 \pm 12.3$ & $61.0 \pm 11.4$ & $65.2 \pm 12.2$ & $60.5 \pm 11.1$ & $64.9 \pm 11.9$ \\
\hline $\begin{array}{l}\text { Reduction rate } \\
\text { of weight (\%) }\end{array}$ & - & - & $0.1 \pm 1.7$ & $-0.2 \pm 1.5$ & $-0.3 \pm 1.8$ & $-0.6 \pm 2.1$ & $-0.6 \pm 1.9$ & $-1.4 \pm 3.0$ & $-1.3 \pm 1.8$ & $-1.6 \pm 4.1$ \\
\hline Mild & - & - & 3 & 6 & 7 & 6 & 8 & 6 & 9 & 5 \\
\hline Moderate & - & - & 0 & 0 & 0 & 1 & 0 & 3 & 0 & 4 \\
\hline Severe & - & - & 0 & 0 & 0 & 0 & 0 & 0 & 0 & 0 \\
\hline \multicolumn{11}{|l|}{ Blood cell counts } \\
\hline $\begin{array}{l}\text { White blood cell } \\
(/ \mu \mathrm{L})\end{array}$ & $6676 \pm 2115$ & $7207 \pm 1972$ & $6536 \pm 1934$ & $6952 \pm 1827$ & $7093 \pm 2164$ & $7170 \pm 2155$ & $6783 \pm 2442$ & $7010 \pm 1729$ & $7087 \pm 2278$ & $6836 \pm 2528$ \\
\hline $\begin{array}{l}\text { Red blood } \\
\text { cell }\left(\times 10^{4} / \mu \mathrm{L}\right)\end{array}$ & $359 \pm 29$ & $356 \pm 42$ & $360 \pm 21$ & $355 \pm 39$ & $360 \pm 37$ & $358 \pm 46$ & $371 \pm 42$ & $353 \pm 39$ & $354 \pm 42$ & $353 \pm 47$ \\
\hline $\begin{array}{l}\text { Platelet } \\
\left(\times 10^{4} / \mu \mathrm{L}\right)\end{array}$ & $21.6 \pm 6.7$ & $20.7 \pm 4.9$ & $20.7 \pm 5.7$ & $19.5 \pm 4.9$ & $22.4 \pm 7.3$ & $18.9 \pm 4.2^{\#}$ & $22.3 \pm 7.6$ & $18.7 \pm 4.3^{\#}$ & $22.1 \pm 6.2$ & $19.5 \pm 4.3$ \\
\hline \multicolumn{11}{|l|}{ Dialysis dose } \\
\hline $\mathrm{Kt} / \mathrm{N}$ & $1.50 \pm 0.26$ & $1.56 \pm 0.23$ & $1.51 \pm 0.25$ & $1.56 \pm 0.22$ & $1.52 \pm 0.27$ & $1.54 \pm 0.22$ & $1.51 \pm 0.25$ & $1.54 \pm 0.21$ & $1.51 \pm 0.26$ & $1.57 \pm 0.24$ \\
\hline
\end{tabular}

MNA screening score: normal nutritional status, 12-14 points; at risk of malnutrition, 8-11 points; malnourished, 0-7 points

Reduction rate of weight (\%): mild, $0-5 \%$; moderate, $5-10 \%$, severe, $\geq 10 \%$

CRP C-reactive protein, \%CGR \% creatinine generation rate, nPCR normalized protein catabolic rate, MNA-SF Mini nutrition Assessment-short form, VAS visual analog scale, $N F$ Filtryzer ${ }^{\circledR} \mathrm{NF}, P S$ polysulfone

${ }^{\#} p<0.05$ vs. baseline; ${ }^{\$} p<0.05$ vs. PS group

remove high molecular weight proteins including albumin by using adsorption. This clinical finding does not lead to a disadvantage on nutrition in NF because this decline was slight and had recovered up to baseline levels after 9 months. Furthermore, this clinical finding was also observed in previous report regarding PMMA dialyzer [5]. There was no significant difference in the rate of body weight change between the NF and PS groups. There were zero and four patients who were considered to show a moderate change of body weight in the NF and PS groups, respectively. Body weight in the NF group tended to be maintained, compared with that of the PS group. In evaluation of MNA-SF score for 12 months, the number of patients who were classified into "at risk of malnutrition" increased from 0 to 2 in the NF group and from 1 to 4 in the PS group. However, there was no significant difference in MNA-SF score compared among each evaluation point during this study and between both groups. Use of NF for 12 months seems not to affect MNA-SF outcome. \%CGR which is an index for estimating muscle mass in dialysis patients was developed by Shinzato et al. [15]. (CGR) is calculated by using pre- and post-dialysis creatinine concentrations. \%CGR is indicated as the percentage of creatinine generation rate CGR in an evaluated dialysis patient to CGR in sex- and age-matched patients without diabetes. In the NF group, \%CGR was maintained for the duration of this study. However, the \%CGR in the PS group tended to decrease at the start of this study and significantly decreased after 6 and 9 months compared with the start of this study. These results may indicate that NF is useful to maintain the patient's 


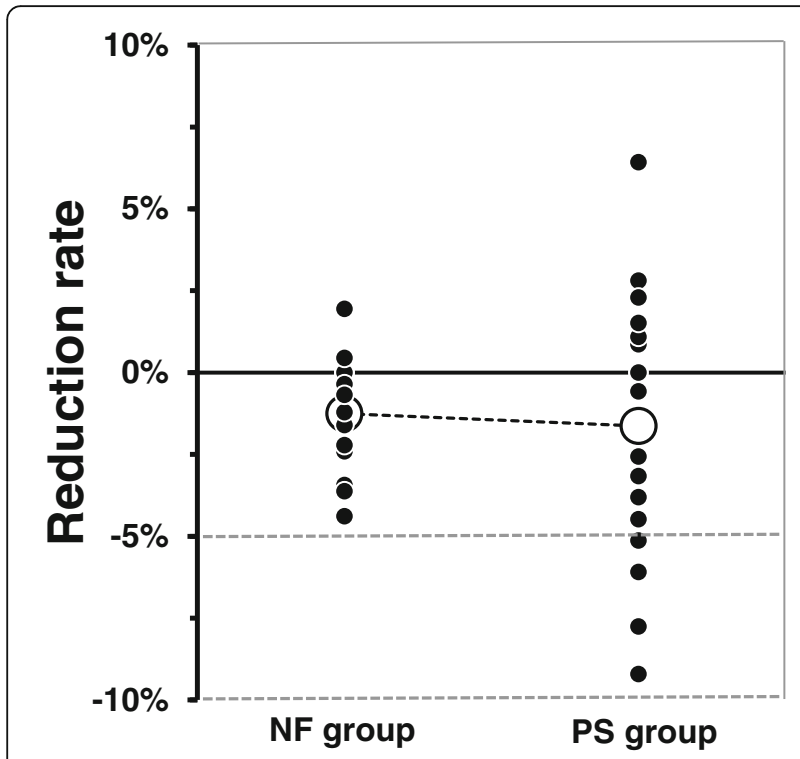

Fig. 2 Body weight reduction rate for 12 months. Filled circles indicate the reduction rate for each patient. Open circles indicate the average values for body weight reduction rate

nutritional condition. It is well known that the patient's nutritional condition is related to inflammation in hemodialysis patients [21], and anti-inflammatory effects of the NF membrane may have contributed to maintaining of the nutritional condition.

Recently, Abe et al. investigated the association between seven types of dialyzers and mortality using data from a nationwide registry of the Japanese Society for Dialysis Therapy $[27,28]$. In Abe et al.'s articles, data were adjusted using basic factors, dialysis dose, nutrition- and inflammation-related factors, with PS as a reference group, and the hazard ratio was significantly lower in the PMMA group compared with the PS group. It is suggested that improvement in the nutritional condition observed in the NF group could lead to a reduction in mortality.

It has been reported that acetate-free dialysate may improve nutrition and inflammation [29]. In our study, acetate-free dialysate had been used in only one dialysis center, and the number of patients who were dialyzed with acetate-free dialysate in NF group was as much as that in PS group. We think that the difference in dialysate did not remarkably affect our results.

In the PS group, platelet counts significantly decreased after 6 and 9 months compared with at the start of this study. The PS membranes are supplied by several manufacturers, and their make-up partially differs. PS membranes contain a hydrophilic polymer, polyvinylpyrrolidone (PVP), and it has been reported that PVP might influence biocompatibility [30]. There were several recent reports about a highly biocompatible PS membrane that uses a new hydrophilic polymer in addition to PVP [31-35]. According to these reports, this new PS membrane has superior biocompatibility compared with conventional PS membranes and could improve conditions in hemodialysis patients compared with conventional PS membranes. Based on the findings described above, we suspect that PS membranes that have inferior biocompatibility may have been included in the PS group in this study. It has been reported that NF has a lower platelet activation property compared with conventional PMMA membranes [12, 13]. Activated platelets release
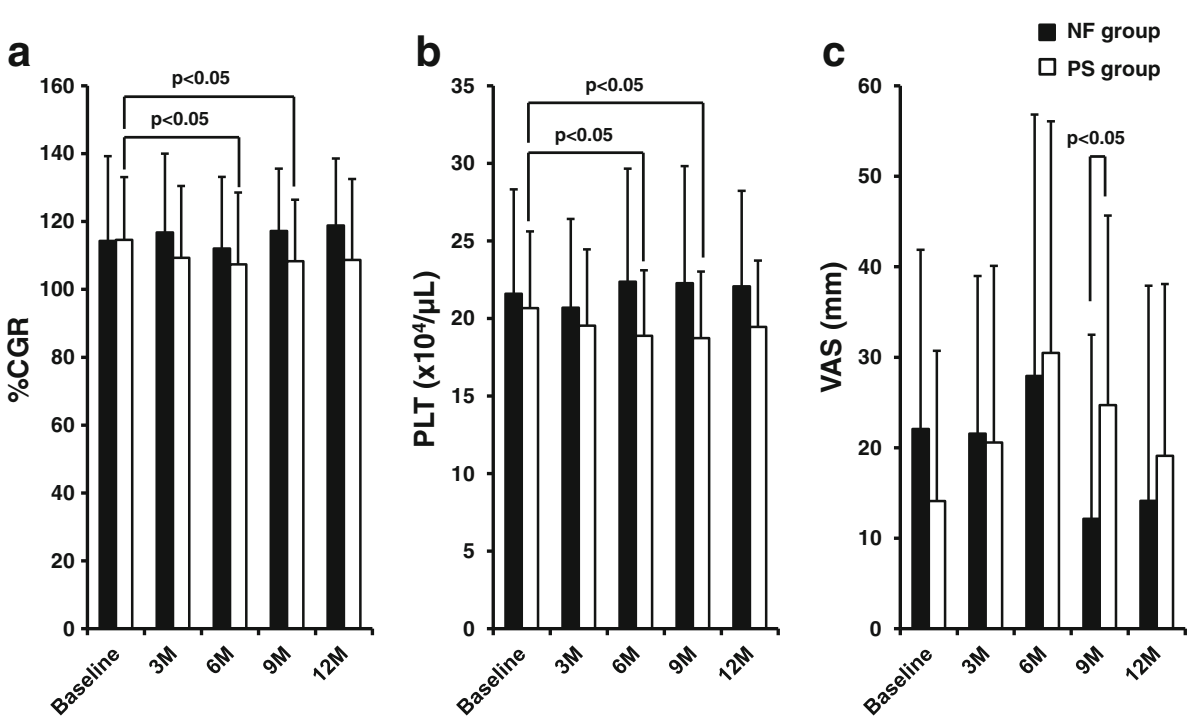

Fig. 3 a-c Change in creatinine generation rate (\%CGR), platelet count, and visual analog scale (VAS) during the study. Filled and open columns indicate results obtained from the PS and NF groups, respectively. The number of patients in the PS and NF groups was 17 and 14 , respectively. Results were expressed as the mean \pm standard deviation 
inflammatory cytokines, and the released cytokines directly and indirectly activate other platelets and lead to a reduction in the platelet count. NF can remove inflammatory cytokines by adsorption. We suggest that the platelet count was maintained in the NF group because of the NF membrane's property of low platelet activation by reforming the membrane surface.

There were several reports that dialysis itchiness was improved using PMMA membranes for a medium- or long-term duration $[8,17]$. In this study, NF could not improve dialysis itchiness at each evaluation point compared with baseline value but VAS value at 9 months in NF group was significantly smaller than PS. In addition, VAS values at 9 and 12 months tended to decrease compared with that of baseline although there was no significant difference. These results indicate that NF as well as conventional PMMA membranes has the potential to improve dialysis itchiness.

Expecting that NF probably improves inflammatory conditions by reducing pro-inflammatory cytokine production from activated platelets and WBCs and by removing serum cytokines via adsorption, we conducted this study. As a result, we found that NF has a potential to maintain nutritional condition and platelet count and improve dialysis itchiness, but we could not observe improvement of PEW. To confirm whether NF can improve dialysis itchiness and PEW or not, we should evaluate again, as considering limitations.

\section{Limitation}

Some limitations exist in this study. First, the number of patient enrolled to this study was small. Second, one patient in NF group was dropped within 3 months by low serum albumin. Third, final dropout rate of NF group was approximately twice as large as that of PS group. Fourth, patients in PS group had received heterogeneous treatments because PS dialyzers were supplied by several manufactures. These might impact our results. We consider that it is desirable for us to conduct a large-scale study excluding these limitations.

\section{Conclusion}

Our results suggest that continuous use of the Filtryzer ${ }^{\circ}$ NF for maintenance hemodialysis patients with chronic inflammation is useful, for maintaining body weight and platelet counts. Large-scale prospective randomized clinical trials are needed to clarify our results.

\footnotetext{
Abbreviations

\%CGR: \% creatinine generation rate; ANOVA: Analysis of variance; BG: Filtryzer ${ }^{\odot}$ BG; CRP: C-reactive protein; KoA: Mass transfer-area coefficient; MIA syndrome: Malnutrition, inflammation, and atherosclerosis syndrome; MNASF: Mini Nutrition Assessment ${ }^{\oplus}$-short form; NF: Filtryzer ${ }^{\oplus} \mathrm{NF}$; nPCR: Normalized protein catabolic rate; PEW: Protein energy wasting; PLT: Platelet; PMMA: Polymethyl methacrylate; PS: Polysulfone; PVP: Polyvinylpyrrolidone: RBCs: Red blood cells; UMIN-CTR: Clinical Trials Registry of the University
}

Hospital Medical Information Network; VAS: Visual analog scale; WBCs: White blood cells

\section{Acknowledgements \\ We thank the Edanz Group (www.edanzediting.com/ac) for editing a draft of this manuscript.}

Availability of data and materials

All data generated or analyzed during this study are included in this article.

Authors' contributions

$\mathrm{NU}, \mathrm{KS}, \mathrm{SS}, \mathrm{YM}, \mathrm{HK}, \mathrm{KT}, \mathrm{KH}, \mathrm{TK}, \mathrm{TW}, \mathrm{Al}, \mathrm{MY}, \mathrm{KO}$, and NM performed the clinical study. NU was a major contributor in writing the manuscript. All authors read and approved the final manuscript.

\section{Ethics approval and consent to participate}

This clinical study was approved by the ethics committee of JCHO Chiba Hospital, and documented informed consent was obtained from each patient.

\section{Consent for publication}

Not applicable.

\section{Competing interests}

The authors declare that they have no competing interests.

\section{Publisher's Note}

Springer Nature remains neutral with regard to jurisdictional claims in published maps and institutional affiliations.

\section{Author details}

${ }^{1}$ Credo Sato Clinic, 2138-1, Wakamatsu-cho, Wakaba-ku, Chiba City, Chiba 264-0021, Japan. ${ }^{2}$ Koyu-kai Himawari Clinic, 2561, Anesaki, Ichihara City, Chiba 299-0111, Japan. ${ }^{3}$ Maeda Institute of Renal Research Mobara Clinic, 114-1, Oshiba, Mobara City, Chiba 297-0033, Japan. ${ }^{4}$ Maeda Institute of Renal Research Ohara Clinic, 1937-2, Ohara, Isumi City, Chiba 298-0004, Japan. 5 Japan Community Health care Organization Chiba Hospital, 682, Nitona-cho, Chuou-ku, Chiba City, Chiba 260-8710, Japan.

Received: 27 February 2018 Accepted: 6 July 2018

Published online: 22 August 2018

\section{References}

1. Buoncristiani U, Galli F, Benedetti S, et al. Quantitative and qualitative assessment and clinical meaning of molecules removed with BK membranes. Contrib Nephrol. 1999:125:133-58.

2. Aoike I. Clinical significance of protein adsorbable membranes-long-term clinical effects and analysis using a proteomic technique. Nephrol Dial Transplant. 2007;22(Suppl 5):v13-9.

3. Galli F, Benedetti S, Buoncristiani U, et al. The effect of PMMA-based proteinleaking dialyzers on plasma homocysteine levels. Kidney Int. 2003;64:748-55.

4. Galli F, Benedetti S, Floridi A, et al. Glycoxidation and inflammatory markers in patients on treatment with PMMA-based protein-leaking dialyzers. Kidney Int. 2005;67:750-9.

5. Yamada S, Kataoka H, Kobayashi $\mathrm{H}$, et al. Identification of an erythropoietic inhibitor from the dialysate collected in the hemodialysis with PMMA membrane (BK-F). Contrib Nephrol. 1999;125:159-72.

6. Locatelli F, Andrulli S, Del Vecchio L. Anemia of hemodialysis patients: evaluation of the effect of BK-F polymethylmethacrylate membrane. Contrib Nephrol. 1999;125:173-81.

7. Akihiko K, Takita T, Furuhashi M, et al. Polymethylmethacrylate efficacy in reduction of renal itching in hemodialysis patients: crossover study and role of tumor necrosis factor-a. Artif Organs. 2001;25:441-7.

8. Lin HH, Liu YL, Liu JH, et al. Uremic pruritus, cytokines, and polymethylmethacrylate artificial kidney. Artif Organs. 2008;32:468-72.

9. Masakane I. High-quality dialysis: a lesson from the Japanese experience. NDT Plus. 2010;3(Suppl 1):i28-35.

10. Contin C, Lacraz A, Precigout V. Potential role of the soluble form of CD40 in deficient immunological function of dialysis patients: new findings of its amelioration using polymethylmethacrylate (PMMA) membrane. NDT Plus. 2010;3(Suppl 1):i20-7. 
11. Duranti E, Duranti D. Polymethylmethacrylate strengthens antibody response hemodialysis patients not responding to hepatitis vaccine: preliminary data. Minerva Med. 2011;102:1-2.

12. Oshihara W, Fujieda H, Ueno Y. A new poly(methyl methacrylate) membrane dialyzer, NF, with adsorptive and antithrombotic properties. Contrib Nephrol. 2017;189:230-6.

13. Masakane I, Esashi S, Yoshida A, et al. A new polymethylmetacrylate membrane improves the membrane adhesion of blood components and clinical efficacy. Renal Replacement Therapy. 2017;3:32.

14. Ridker PM. High-sensitivity C-reactive protein. Potential adjunct for global risk assessment in the primary prevention of cardiovascular disease. Circulation. 2001;103:1813-8.

15. Shinzato T, Nakai S, Miwa M, et al. New method to calculate creatinine generation rate using pre- and postdialysis creatinine concentrations. Artif Organs. 1997:21:864-72.

16. Vellas $B$, Villars $H$, Abellan $G$, et al. Overview of $M N A^{\oplus}$ - its history and challenges. J Nut Health Aging. 2006;10:456-65.

17. Aucella F, Vigilante M, Gesuete A, et al. Uraemic itching: do polymethylmethacrylate dialysis membranes play a role? Nephrol Dial Transplant. 2007;22(Suppl 5):v8-12.

18. Kalantar-Zadeh K, Kopple JD. Relative contributions of nutrition and inflammation to clinical outcome in dialysis patients. Am J Kidney Dis. 2001; 38:1343-50.

19. Kawanishi H, Akiba T, Masakane I, et al. Standard on microbiological management of fluids for hemodialysis and related therapies by the Japanese Society for Dialysis Therapy 2008. Ther Apher Dial. 2009;13:161-6.

20. Johansen $\mathrm{KL}$, Kaysen GA, Young BS, et al. Longitudinal study of nutritional status, body composition, and physical function in hemodialysis patients. Am J Clin Nutri. 2003;77:842-6.

21. Stenvinkel P. Can treating persistent inflammation limit protein energy wasting? Semin Dial. 2013;26:16-9.

22. Sakamoto $Y$, Mashiko $K$, Obata $T$, et al. Effectiveness of continuous hemodiafiltration using a polymethylmethacrylate membrane hemofilter after polymyxin B-immobilized fiber column therapy of septic shock. ASAIO J. 2008;54:129-32.

23. Aukrust $\mathrm{P}$, Halvorsenu, Ueland $\mathrm{T}$, et al. Activated platelets and atherosclerosis. Expert Rev Cardiovasc Ther. 2010;8:1297-307.

24. Weyrich AS, Elstad MR, McEver RP, et al. Activated platelets signal chemokine synthesis by human monocytes. J Clin Invest. 1996;97:1525-34

25. Koenig W, Sund M, Fröhlich $M$, et al. C-reactive protein, a sensitive marker of inflammation, predicts future risk of coronary heart disease in initially healthy middle-aged men: results from the MONICA (monitoring trends and determinants in cardiovascular disease) Augsburg cohort study, 1984 to 1992. Circulation. 1999:9:237-42.

26. Tomiyama H, Okazaki R, Koji Y, et al. Elevated C-reactive protein: a common marker for atherosclerotic cardiovascular risk and subclinical stages of pulmonary dysfunction and osteopenia in a healthy population. Atherosclerosis. 2005;178:187-92.

27. Abe M, Hamano T, Wada A, et al. Effect of dialyzer membrane materials on survival in chronic hemodialysis patients: results from the annual survey of the Japanese Nationwide Dialysis registry. PLoS One. 2017;12:e0184424.

28. Abe M, Hamano T, Wada A, et al. High-performance membrane dialyzers and mortality in hemodialysis patients: a 2-year cohort study from the annual survey of the Japanese Renal Data Registry. Am J Nephrol. 2017;46:82-92.

29. Kuragano T, Kida A, Furuta M, et al. Effects of acetate-free citrate-containing dialysate on metabolic acidosis, anemia, and malnutrition in hemodialysis patients. Artif Organs. 2012:36:282-90

30. Daugirdas JT, Bernardo AA. Hemodialysis effect on platelet count and function and hemodialysis-associated thrombocytopenia. Kidney Int. 2012;82:147-57.

31. Yamaka T, Ichikawa K, Saito M, et al. Biocompatibility of the new anticoagulant dialyzer TORAYLIGHT NV. Science Postprint. https://doi.org/10. 14340/spp.2014.05C0002.

32. Hidaka S, Kobayashi S, Maesato K, et al. Hydrophilic polymer-coated polysulfone membrane improves endothelial function of hemodialysis patients: a pilot study. J Clin Nephrol Res. 2015;2:1020.

33. Kakuta $\mathrm{T}$, Komaba $\mathrm{H}$, Takagi $\mathrm{N}$, et al. A prospective multicenter randomized controlled study on Interleukin-6 removal and induction by a new hemodialyzer with improved biocompatibility in hemodialysis patients: a pilot study. Ther Apher Dial. 2016;20:569-78.
34. Ronco C, Brendolan A, Nalesso F, et al. Prospective, randomized multicenter, controlled trial (TRIATHRON 1) on a new antithrombogenic hydrophilic dialysis membrane. Int J Artif Organs. 2017:40:234-9.

35. Tsuchida K, Hashimoto H, Kawahara K, et al. Effects of hydrophilic polymercoated polysulfone membrane dialyzers on intradialytic hypotension in diabetic hemodialysis patients (ATHRITE BP study): a pilot study. Renal Replacement Therapy. 2017;3:58.
Ready to submit your research? Choose BMC and benefit from:

- fast, convenient online submission

- thorough peer review by experienced researchers in your field

- rapid publication on acceptance

- support for research data, including large and complex data types

- gold Open Access which fosters wider collaboration and increased citations

- maximum visibility for your research: over $100 \mathrm{M}$ website views per year

At $\mathrm{BMC}$, research is always in progress.

Learn more biomedcentral.com/submissions 